УДК 519.853.4

MSC 90C26

\title{
PRACTICAL EFFICIENCY OF EQR METHOD FOR SOLVING GLOBAL OPTIMIZATION PROBLEMS
}

\author{
A. I. Kosolap
}

Faculty of Computer Science and Engineering, University of Chemical Engineering, Dnipro, Ukraine, E-mail: anivkos@ua.fm

\section{ПРАКТИЧНА ЕФЕКТИВНІСТЬ МЕТОДУ ЕQR ДЛЯ РОЗВ'ЯЗУВАННЯ ЗАДАЧ ГЛОБАЛЬНОЇ ОПТИМІЗАЦЇ̈}

\author{
А. І. КОСОЛАП
}

Факультет комп'ютерних наук та інженерії, Український державний хіміко-технологічний університет, Дніпро, Україна, E-mail: anivkos@ua.fm

\begin{abstract}
This article provides an analysis the practical effectiveness of the method of exact quadratic regularization. Significant computational experiments have been performed to solve the complex multi-modal test and practical problems. The results of computational experiments are compared with the best results obtained by existing methods of global optimization. Comparative analysis shows a much greater practical efficiency of the method of exact quadratic regularization.

KEYWORDS: multi-modal problems, global optimization, numerical experiments, exact quadratic regularization method.

АнотАція. В статті проводиться аналіз практичної ефективності методу точної квадратичної регуляризації. Проведені значні обчислювальні експерименти з розв'язування складних мультимодальних тестових та практичних задач. Результати обчислювальних експериментів порівнюються з кращими результатами, що отримані існуючими методами глобальної оптимізації. Порівняльний аналіз свідчить про значно більшу практичну ефективність методу точної квадратичної регуляризації.

КлючовІ СловА: мультимодальні задачі, глобальна оптимізація, обчислювальні експерименти, метод точної квадратичної регуляризації.
\end{abstract}

\section{ВСТУП}

Перші дослідження в галузі глобальної оптимізації з'явились тільки в середині минулого століття. Це при тому, що екстремальні задачі цікавили дослідників ще до нашої ери. Причина цього феномену криється в тому, що в часи П. Ферма (період заснування математичного аналізу) вивчались в 
основному поліноміальні функції однієї змінної. Кількість локальних екстремумів таких функцій не перевищує $n-1$, де $n$ - ступінь поліному. Тому легко знайти всі екстремуми функції і обрати серед них глобальний екстремум. На декілька століть головним засобом розв'язування екстремальних задач був математичний аналіз, який не дозволяє розрізняти точки локального і глобального екстремуму. Тому в рамках математичного аналізу проблема пошуку глобального екстремуму не була актуальною.

3 розвитком математичного моделювання в 20 столітті з'являються моделі прикладних задач, які мають $2^{n}, n$ ! та більше локальних екстремумів. Це, наприклад, задачі з булевими змінними в яких розв'язок знаходиться в вершинах гіперкубу, чи задачі теорії розкладу з $n$ ! локальними екстремумами. Крім того багато моделей прикладних задач містять десятки і сотні тисяч змінних. Зрозуміло, що для таких моделей перебрати всі локальні екстремуми навіть за допомогою комп'ютера неможливо. Потрібно було розробити новий аналіз для знаходження глобального екстремуму.

В 20 столітті був розроблений опуклий аналіз спочатку в геометрії, а пізніше в середині століття його почали використовувати в оптимізації. В цей же час з'являються перші роботи присвячені пошуку глобального екстремуму $[1,2]$. Для опуклих задач були розроблені практично ефективні алгоритми оптимізації, які дозволяють легко знайти точку глобального екстремуму (опуклі задачі є унімодальними).

Але клас опуклих моделей досить незначний. Майже кожна практична задача оптимізації є мультимодальною (містить безліч локальних екстремумів). Спроба протягом десятків років знайти мультимодальні класи задач $з$ ефективними алгоритмами пошуку глобального екстремуму не дали результату. Задачі угнутої, reverse-convex, DC оптимізації та загальні квадратичні задачі виявились такими ж складними, як і загальна задача глобальної оптимізації.

Значно більше зусиль було витрачено на розробку ефективних алгоритмів для задач з дискретними змінними, які теж є мультимодальними. Але і для цього класу задач не було розроблено ефективних алгоритмів. В 70$\mathrm{x}$ роках минулого століття була розроблена теорія складності, згідно якої алгоритми і задачі були поділені на два класи Р (поліноміальні) і NP (неполіноміальні). Звичайно клас мільтимодальних задач є NP-складним. Але ця складність доводиться для всього класу задач і невідомо, яка частина цього класу є NР-складною.

Проблеми в розв'язуванні мультимодальних задач призвели до використання опуклої релаксації. Але така релаксація дозволяє отримати тільки оцінку глобального екстремуму. Іноді така оцінка досить далека від глобального екстремуму. В наш час опукла релаксація у поєднанні з методами розгалужень та границь використовується в сучасних програмних пакетах для розв'язування мультимодальних задач. Наприклад, такий відомий пакет, як BARON показує ефективність порядку $80 \%$ (правильних розв'язків) на тестових мультимодальних задачах з відомими розв'язками. Така 
ефективність досягається не для всіх задач, наприклад, цей пакет не використовується для мультимодальних задач, які містять тригонометричні функції.

Важливою віхою в розвитку глобальної оптимізації була розробка напіввизначеного програмування в кінці минулого століття [3]. Цей напрям теж використовує опуклу релаксацію і використовується для розв'язування квадратичних та поліноміальних задач. Але напіввизначене програмування дозволяє отримувати теж тільки оцінки глобального екстремуму. Отримані оцінки можна використовувати для подальшої локальної оптимізації.

Проблеми, пов'язані зі знаходженням глобального екстремуму призвели до широкого використання стохастичних методів [4]. 3'являються генетичні, еволюційні та інші алгоритми, які використовують випадковий пошук. Такі алгоритми містять досить багато параметрів, налаштування яких для конкретної задачі дає змогу іноді отримувати точку глобального екстремуму для тестових мультимодальних задач. Але досить часто такі алгоритми дозволяють отримати розв'язки далекі від оптимальних. Крім того, підвищення ефективності таких алгоритмів малоймовірно.

Більш детальний аналіз сучасного стану в глобальній оптимізації представлений в роботі [5]. 3 цієї роботи випливає, що глобальна оптимізація досить складна галузь досліджень і нам марно очікувати практично ефективних алгоритмів для знаходження глобальних екстремумів. Підтвердженням цієї тези є те, що мультимодальні задачі, як правило, відносяться до NP-повних задач, для розв'язування яких не розроблено ефективних поліноміальних алгоритмів.

Тоді виникає питання, а чи можна розробити алгоритм для розв'язування мультимодальних задач, який буде ефективним для більшості практичних мультимодальних задач? Такий приклад ми бачимо в лінійному програмуванні. Не дивлячись на те, що симплекс-метод є неполіноміальним, він вже більше 70 років успішно використовується для розв'язування лінійних задач. Розробка такого методу для мультимодальної оптимізації $\epsilon$ ще більш актуальною задачею, оскільки клас мультимодальних задач $є$ досить великий та складний. Завжди можна знайти мультимодальні задачі для яких будь-який метод зустрінеться зі значними обчислювальними проблемами. Але це будуть, як правило, не практичні, а штучні мультимодальні проблеми. Тому практична ефективність сучасних нових методів глобальної оптимізації перевіряється шляхом розв'язування розроблених тестових та практичних мультимодальних задач. Ці задачі досить відомі і знаходяться в базах Globallib Model Statistics та Minlplib Model Statistics (всього 668 задач) за адресами [6] та [7], які легко знайти в мережі Internet. Також велика база мультимодальних задач (більше 1000) представлена в Princeton Library of Nonlinear Programming Models за адресом [8]. Ці бази створювались 20 років тому і вже двадцять років на задачах з даних баз перевіряються нові та існуючи алгоритми і програми глобальної оптимізації. Крім того, існує біля 200 тестових функцій безумовної глобальної оптимізації [9]. 


\section{1. ПОСТАНОВКА ЗАДАЧІ}

Розглядаються мультимодальні задачі в евклідовому просторі. Треба знайти екстремальне (мінімальне або максимальне) значення цільової функції $n$ змінних на заданій множині, яка є компактною. Допустима множина визначається системою рівнянь або нерівностей для функцій. Цільова функція та функції обмежень є неперервними та, як правило, двічі диференційовані. Потрібно знайти точку глобального екстремуму цільової функції на допустимій множині розв'язків системи рівнянь та нерівностей.

\section{2. АНАЛІЗ ТЕСТОВИХ ЗАДАЧ}

Тестові задачі безумовної оптимізації, як правило, мають безліч локальних екстремумів. Більшість таких задач побудовано з відомими значеннями глобального мінімуму та точкою в якій він досягається. Багато тестових задач мають невелику розмірність, зокрема два. Частина задач мають довільну розмірність. Значення глобального мінімуму в тестових задачах Egg holder та Rana для $n \geq 10$ невідомо. Деякі задачі розмірності два з нетривіальними розв'язками можна узагальнити на довільну розмірність. Так, автор узагальнив наступні задачі: Adjman, Bird, Mishra 6, NewFunction 03, Scahffer 4, Trefethen на довільну розмірність. Ці задачі є несепарабельними, тому для них значення глобального мінімуму для $n>2$ невідомо. Вони мають безліч локальних мінімумів. Але тестові задачі безумовної оптимізації, як правило, є симетричними (функціональна залежність для пар змінних часто співпадає). Це означає, що значення багатьох компонент точки глобального мінімуму будуть співпадати.

Можна зробити висновок, що відомі тестові задачі безумовної оптимізації не досить інформативні для перевірки практичної ефективності методів глобальної оптимізації. Потрібно обмежитись несепарабельними мультимодальними тестовими функціями з невідомими розв'язками, так як відомі розв'язки завжди можна отримати після тривалих численних експериментів шляхом відповідного підбору багаточисельних параметрів. Якщо значення глобального мінімуму невідомо, то кращий метод знайде кращий розв'язок ніж розв'язок, отриманий менш ефективним методом.

Задачі умовної оптимізації із приведених вище баз, як правило, є моделями прикладних задач. Переважна більшість задач з цих баз є квадратичними, частіше з квадратичними обмеженнями. Ці бази також містять багато задач малої розмірності, але є достатньо задач середньої та великої розмірності. Глобальний мінімум для більшості цих задач невідомий, але протягом 20 років були знайдені нижні оцінки розв'язків.

Можна говорити, що в цих задачах точка глобального мінімуму відома, якщо нижня оцінка співпадає з верхньою. Для задач умовної оптимізації виникає проблема точності виконання обмежень. Інколи незначна зміна точності виконання обмежень призводить до значної зміни цільової функції. Якщо замість нуля обмеження дорівнюють $1 e-10$, то таку точність можна вважати достатньою. 
В наш час, майже кожна робота з глобальної оптимізації містить обчислювальні експерименти. В цих експериментах приводятся дані, отримані новими або модіфікованими методами. Іноді отримані результати краще існуючих, але перевірити отримані результати майже неможливо, так як точки глобального мінімуму, як правило, не приводятся. Добре, що приведені вище бази для більшості задач містять кращі розв'язки, які отримані на даний час.

\section{3. МЕТОД ТОЧНОї КВАДРАТИЧНОЇ РЕГУЛЯРИЗАЦІї (EQR)}

Метод EQR був започаткований автором цієї статті ще 10 років тому. Протягом цього часу метод EQR постійно вдосконалювався та пройшов значну обчислювальну перевірку при розв'язуванні безлічі складних мультимодальних задач. Його теоретичне обгрунтування приведено в статті [10] та інших публікаціях автора. Квадратична регуляризація використовується для перетворення загальної задачі глобальної оптимізації

$$
\min \left\{f_{0}(x) \mid f_{i}(x) \leq 0, i=1, \ldots, m, x \in E^{n}\right\},
$$

до наступної

$$
\begin{aligned}
\max \left\{\|z\|^{2} \mid f_{0}(x)+s+(r-1)\|z\|^{2} \leq d,\right. & \\
& \left.f_{i}(x)+r\|z\|^{2} \leq d, \quad i=1, \ldots, m, \quad z \in E^{n+1}\right\},
\end{aligned}
$$

де $z=\left(x_{1}, \ldots, x_{n}, x_{n+1}\right)$, параметр $r$ обираємо таким, щоб допустима множина задачі (2) стала опуклою, а параметр $s$ повинен задовольняти умові

$$
s \geq\left\|x^{*}\right\|^{2}-f_{0}\left(x^{*}\right),
$$

де $x^{*}$ - розв'язок задачі (1), $d$ - скаларна величина, яку потрібно знайти. В задачі (2) нас цікавлять тільки ті розв'язки, для яких виконується умова

$$
r\|z\|^{2}=d
$$

(будемо називати цю умову SP-умовою). Такі розв'язки відповідають точкам локальних мінімумів задачі (1).

Очевидно, що при $r \rightarrow+\infty$ для довільних неперервних функцій задачі (1) допустима множина задачі (1) буде опуклою. Інколи задача (2) буде унімодальною, незважаючи на те, що задача (1) мультимодальна (див. [11]). Крім того, якщо опукла множина задачі (2) є центрально симетричною (паралелепіпед, правильний многогранник та інше), то задача (2) еквівалентна опуклій задачі

$$
\max \left\{c^{T} z \mid f_{0}(x)+s+(r-1)\|z\|^{2} \leq d, \quad f_{i}(z)+r\|z\|^{2} \leq d, \quad i=1, \ldots, m\right\} .
$$

де точка $c$ - центр симетрії опуклої множини. Можна привести інші випадки для яких задача (2) буде унімодальною. Наприклад, якщо кривизна опуклої поверхні допустимої множини в кожній точці $y$ більше кривизни сфери $r\|z\|^{2}=r\|y\|^{2}$, то задача (2) теж буде унімодальною. Точна квадратична регуляризація упорядковує точки локальних мінімумів задачі (1) таким чином, що мінімальному значенню $d>0$, при якому розв'язок задачі (2) задовольняє SP-умові, відповідає глобальний мінімум задачі (1). 
Метод EQR полягає в тому, що обирається значення параметрів задачі (2), розв'язується задача опуклої оптимізації для знаходження мінімального значення $d$

$$
\min \left\{d \mid f_{0}(x)+s+(r-1)\|z\|^{2} \leq d, \quad f_{i}(z)+r\|z\|^{2} \leq d, \quad i=1, \ldots, m\right\} .
$$

і здійснюється подальша зміна скалярної величини $d$ та розв'язок задачі (2) для кожного фіксованого значення $d$ до виконання SP-умови.

Частіше всього при розв'язуванні мультимодальних задач нев'язка

$$
\Delta=\left.|r||x|\right|^{2}-d \mid,
$$

отримана з розв'язку опуклої задачі (3), швидко збігається до нуля при зміні скалярної величини $d$ і розв'язуванні задачі (2) будь-якою програмою локальної оптимізації. Інколи для отримання точки глобального мінімуму потрібно менше 10 ітерацій. Значення цільової функції $f_{0}(x)$, отримане 3 розв'язку опуклої задачі теж зменшується на кожній ітерації. Інколи воно після розв'язування задачі (3) значно менше значення глобального мінімуму задачі (1) і тоді на кожній ітерації значення цільової функції зростає. Нагадуємо, що параметр $s$ повинен задовольняти умові

$$
s \geq\left\|x^{*}\right\|^{2}-f_{0}\left(x^{*}\right),
$$

тому якщо на якійсь ітерації ця умова порушується, то необхідно збільшити значення $s$ та продовжити пошук глобального мінімуму. Головна мета методу EQR при зміні скалярної величини $d$ не пропустити точку глобального мінімуму, адже для $d<d^{*}$ точок локального мінімуму задачі $(2)$ не існує.

Головна проблема існуючих методів глобальної оптимізації застрявання в точках локального мінімуму. Метод $\mathrm{EQR}$ дозволяє легко проходити точки локальних мінімумів, що можна показати на простому прикладі мультимодальної функції

$$
f_{0}(x)=(x-1)(x-2)(x-3)(x-5) .
$$

Будь-яка програма локальної оптимізації буде знаходити точку локального мінімуму 1,393 цієї функції, якщо початкову точку обрати на інтервалі $(-\infty, 3]$ і точку глобального мінімуму 4,326 , якщо початкову точку обирати на інтервалі $(3,+\infty)$. Точка глобального мінімуму цієї функції буде знаходитись далі від початку координат, ніж точка локального мінімуму. Але для перетвореної задачі (2) точка глобального мінімуму буде завжди ближче до початку координат. Якщо ми скористаємося будь-якою програмою локальної оптимізації, то майже для довільної початкової точки програма буде знаходити точку глобального мінімуму, навіть якщо початкова точка знаходиться в точці локального мінімуму $(1,393,1)$.

Проходження точок локальних мінімумів одна з головних причин практичної ефективності методу EQR (можна допустити, що квадратична регуляризація згладжуе точки локальних мінімумів).

Таким чином, для більшості мультимодальних практичних задач метод EQR дозволяє знаходити точку глобального мінімуму так легко, як і точку 
локального мінімуму. Але існують достатньо складні тестові задачі зі значною кількістю локальних мінімумів для яких запропонований метод EQR потребує модифікації.

Однією з модифікацій є зсув допустимої опуклої множини задачі (2) впродовж бісектриси додатного ортанту (вектору, що проходить через точку $(1, \ldots, 1))$. Такий зсув не змінюе кривизну опуклої поверхні допустимої множини та зменшуе кривизну поверхні кулі. Це дозволяе уже при розв'язуванні опуклої задачі (3) отримувати краще значення цільової функції $f_{0}(x)$ та менше значення нев'язки $\Delta$.

Покажемо даний ефект на прикладі відомої та досить складної функції Langerman [9] для $n=10$. Більшість експериментів показує краще мінімальне значення цієі функції $-0,965$. Автор замість мінімізації $f_{0}(x)$ розглядав мінімізацію $f_{0}(x-h), h=4$ функції Langerman. Уже при розв'язуванні відповідної опуклої задачі (3) при значеннях параметрів $s=1500$, $r=50$ було знайдено

$$
f_{0}(x)=-0,97813
$$

що краще приведеного вище значення. Мінімальне значення $d_{0}=27588,976$, отримане з розв'язку задачі (3). При збільшенні значення $d$ до $30000 \mathrm{i}$ розв'язуванні задачі (2) було отримано точку мінімуму $x^{*}$, для якої $f_{0}\left(x^{*}\right)=$ $-1,5$. Подальше збільшення скалярної величини $d$ не призвело до зменшення $f_{0}(x)$. Таким чином, за три ітерації було отримано кращий розв'язок.

Для досить складної функції Bird (функція узагальнена автором на довільну розмірність)

$$
\begin{array}{r}
\min \left\{\sum_{i=1}^{n-1}\left(\sin \left(x_{i}\right) e^{\left(1-\cos \left(x_{i=1}\right)\right)^{2}}+\cos \left(x_{i}\right) e^{\left(1-\sin \left(x_{i=1}\right)\right)^{2}}-\left(x_{i}-x_{i+1}\right)^{2}\right) \mid\right. \\
\left.x \in[-2 \pi, 2 \pi]^{n}\right\}
\end{array}
$$

кращий розв'язок було отримано за декілька ітерацій при зсуві допустимої опуклої множини відповідної задачі (2) на величину $h=3,5$ та збільшення величини параметру $r$ до значення 500, значення параметру $s=10000$. Отримано мінімальне значення цієї функції $-5230,329$ для $n=100$, що значно краще ніж розв'язок $-4097,8487$, отриманий еволюційним пошуком з бібліотеки Python.

Можна було використати інші пакети глобальної оптимізації, але вони для такої розмірності даної задачі потребують досить багато часу. Задача 3 функцією Bird для $n=100$ не розв'язувалась іншими авторами, так як в літературі вона розглядається тільки для $n=2$.

Можна привести досить складну функцію Adjman, яка теж узагальнена автором на довільну розмірність

$$
\min \left\{\sum_{i=1}^{n-1} \cos \left(x_{i}\right) \sin \left(x_{i+1}\right)+\sum_{i=1}^{n} \frac{x_{i}}{x_{i+1}^{2}+1} \mid x \in[-1,1]^{n}\right\} .
$$

Для цієї функції майже кожна початкова точка є локальним мінімумом. Задача з цією функцією розв'язувалась також для $n=100$. Значення зсуву 
допустимої множини було $h=1$, після якого розв'язок знаходився в додатному ортанті. Значення параметрів обиралось наступні $r=60, s=1500$. Знайдений глобальний мінімум -30,374 за 10 ітерацій (під ітерацією ми розуміємо кількість розв'язків задачі (2) при різних значеннях скалярної величини $d$ ), що значно краще розв'язку $-23,3046$, що отриманий еволюційним пошуком з бібліотеки Python.

На відміну від розглянутих функцій, які узагальнені на довільну розмірність і не аналізувались іншими авторами, функції Egg holder та Rana для $n=100$ мінімізуються багатьма авторами уже протягом більш ніж 20 років, але жоден з існуючих методів не показав кращих результатів ніж результати, отримані методом EQR.

Для функції Egg holder

$$
f_{0}(x)=-89948,532
$$

та для функції Rana

$$
f_{0}(x)=50865,131 \text {. }
$$

Взагалі, ефективність методу EQR залежить від вибору значень параметрів $r, s$ та величини зміни скалярної величини $d$.

\section{4. РЕЗУЛЬТАТИ ОБЧИСЛЮВАЛЬНИХ ЕКСПЕРИМЕНТІВ}

Для перевірки практичної ефективності методу EQR автором було розв'язано біля 500 відомих складних мультимодальних тестових задач з приведених вище баз та тестових задач безумовної оптимізації. Більше 300 таких задач з розв'язками представлені в книзі автора [11].

Автор не розв'язував задачі малої розмірності, зокрема для $n=2$ яких багато в приведених базах. Автор не розв'язував також задачі великої розмірності $(n>500)$. Метод EQR призначений і для розв'язування таких задач, але для цього потрібно мати ефективну програму локальної оптимізації. Якщо не враховувати задачі малої та великої розмірності, а також деякі задачі умовної оптимізації з відомими розв'язками, то методом EQR були розв'язані майже всі задачі з приведених баз.

Крім того, розв'язувались такі відомі та складні задачі, як мінімізація потенційної енергії атомів, упаковка кругів в квадрат і круг, максимізація надійності систем, задачі теорії розкладу, відомі інженерні задачі з механіки, задачі з булевими змінними та інші прикладні задачі.

Результати експериментів свідчать про високу практичну ефективність методу EQR.

Для більшості тестових та прикладних задач розв'язки збіглися з кращими розв'язками, отриманими іншими авторами на сьогоднішній день. Зокрема, збіглися розв'язки для задач мінімізації потенціальної енергії атомів різної розмірності, задачі упаковки кругів та інші. Але майже в $30 \%$ розв'язаних задач були отримані кращі розв'язки. Деякі з таких розв'язків ми наводимо в наступній табл. 1 (приведені задачі були розв'язані після публікації [11]). 
ТАБл. 1. Результати обчислювальних експериментів

\begin{tabular}{|c|c|c|c|c|c|}
\hline Задача & $n$ & $m$ & $\begin{array}{r}\text { Розв'язок } \\
\text { методом EQR }\end{array}$ & $\begin{array}{c}\text { Кращий } \\
\text { відомий } \\
\text { розв'язок }\end{array}$ & Літ. \\
\hline Egg holder & 100 & 0 & -89948.532 & -89938 & [9] \\
\hline Rana & 100 & 0 & -50865.131 & -43880 & [9] \\
\hline Bird & 100 & 0 & $-5230,3293$ & $-4097,8487$ & [9] \\
\hline Adjman & 100 & 0 & $-30,37418$ & $-23,30464$ & [9] \\
\hline dipigri & 7 & 4 & 80,63202 & 680,6301 & [8] \\
\hline Prob07 & 14 & 35 & 154990,229 & 155153,544 & [7] \\
\hline Chain50 & 102 & 51 & 0,09259 & 5,07226 & {$[6]$} \\
\hline Ex3 & 32 & 31 & 60,5531381 & 68,0097 & [7] \\
\hline Ex $8 \_3 \_8$ & 126 & 93 & $-10,00001$ & $-3,256$ & {$[6]$} \\
\hline btest14 & 135 & 93 & $-10938,246$ & $-59,81738781$ & {$[6]$} \\
\hline waterx & 70 & 55 & 891,8463569 & 909,0278626 & [7] \\
\hline waterz & 195 & 138 & 906,998 & 907,017 & {$[7]$} \\
\hline minlphi & 65 & 47 & 568,9207 & 582,2361 & {$[6]$} \\
\hline pump & 24 & 34 & 16139,84 & 128893,74 & {$[6]$} \\
\hline Ex8_2_4b & 62 & 88 & -1644.23 & -1197.13 & {$[6]$} \\
\hline Ex $8 \_3 \_7$ & 126 & 92 & $-7,18881$ & $-1,2326$ & {$[6]$} \\
\hline Ex8_3_11 & 116 & 76 & -10 & $-0,7921$ & {$[6]$} \\
\hline korcge & 95 & 77 & $-521,1160511$ & $-339,213$ & {$[6]$} \\
\hline deb10 & 183 & 130 & 39,99998 & 90 & [7] \\
\hline grouping & 100 & 125 & $-1035,89887$ & 13,8504 & [8] \\
\hline dnieper & 61 & 24 & 14057,36 & 17134,4533 & [8] \\
\hline optctrl6 & 122 & 80 & 606,48066 & 2048,017 & [8] \\
\hline eigminb & 101 & 101 & 0,000967 & 0,27316 & [8] \\
\hline
\end{tabular}

Ми можемо навести знайдені точки мінімуму для приведених вище задач, але для цього потрібно декілька сторінок заповнити цифрами. Приведемо розв'язок тільки двох задач з табл. 1 не великої розмірності dipigri та Prob07. Розв'язок, отриманий методом EQR задачі dipigri $€$

$$
x^{*}=(1,73358 ;-0,37244 ;-0,22448 ; 5,56808 ;-0,57153 ; 0,93086 ; 1,71381)
$$

для якого $f_{0}\left(x^{*}\right)=80,63202$. В базі [8] знаходимо кращий розв'язок, отриманий іншими методами $f_{0}\left(x^{*}\right)=680,6301$, що значно поступається результату, знайденому методом EQR.

Наведемо також розв'язок задачі Prob07, отриманий методом EQR

$x^{*}=(1153,824 ; 1203,336 ; 859,5257 ; 859,5257 ; 769,2161 ; 859,5257 ; 1648,054$;

$343,8103 ; 343,8103 ; 458,2657 ; 458,2657 ; 6,6258478 ; 10,517806 ; 7,0007267)$

для якого $f_{0}\left(x^{*}\right)=154990,229$. Точність виконання обмежень $1 e-10$.

В базі Globallib Model Statistics легко знаходимо кращий розв'язок на сьогоднішній день для цієї задачі $f_{0}(x)=155153,544$, який досягається в 
точці

$$
\begin{aligned}
& x^{*}= \\
& =(1100,5386 ; 1279,5372 ; 913,9552 ; 913,9552 ; 733,6924 ; 913,955 ; 1399,1684 ; \\
& \quad 365,57973 ; 365,5797 ; 459,6259 ; 459,6259 ; 6,78386 ; 10,39443 ; 7,13618) .
\end{aligned}
$$

3 табл. 1 бачимо, що цей розв'язок значно поступається розв'язку, отриманому методом EQR.

\section{Висновки}

Наведені результати обчислювальних експериментів яскраво свідчать про високу практичну ефективність методу EQR. Фактично цей метод дозволяє розв'язувати мультимодальні задачі так легко, як розв'язуються задачі опуклої оптимізації.

Цей метод відкидає впевненість, що «побудова ефективного неспеціалізованого алгоритму глобальної оптимізації малоймовірна, а можлива тільки розробка методів, призначених для дуже вузьких класів функцій» (див. [12], с. 270). Історія глобальної оптимізації показала прямо протилежне, що не існує таких вузьких практично важливих функцій, а можлива розробка практичного ефективного алгоритму для загальної задачі глобальної оптимізації.

\section{ЛIтеРАТУРА}

1. Hoang Tuy Concave programming with linear constraints. Dokl. Akad. Nauk SSSR. 1964. Vol. 159. No. 1. P. 32-35.

2. Falk J. E., Soland R. M. Separable nonconvex programming by branch and bound. Management Sci. 1969. 15 (9). P. 550-569.

3. Vandenberghe L., Boyd S. Semidefinite programming. SIAM Review. 1996. Vol. 38. P. 49-95.

4. Kenneth V. P., Storn R. M., Lampinen J. A. Differential Evolution. A Practical Approach to Global Optimization. Berlin, Heidelberg: Springer, 2005. 542 p.

5. Marco Locatelli, Fabio Schoen (Global) Optimization: Historical notes and recent developments. EURO J. on Computational Optimization. 2021. Vol. 9. P. 1-15.

6. http://www.gamsworld.org/global/globallib/globalstat.htm.

7. http://www.gamsworld.org $/ \mathrm{minlp} / \mathrm{minlplib} / \operatorname{minlpstat} . h t m$.

8. http://www.gamsworld.org / $\mathrm{minlp} / \mathrm{minlplib} /$ minlpstat.htm.

9. Jamil M., Yang X. S. A literature survey of benchmark functions for global optimization problems. Int. J. Math. Model Numer. Optim. 2013. Vol. 4. No. 2. P. 150-194.

10. Kosolap A. A new method for global optimization. ESAIM: Proceedings and Surveys. August 2021. Vol. 71. P. 121-130.

11. Kosolap A. Practical Global optimization. Dnipro: Publ. Bila K.O., 2020. 192 p.

12. Numerical Methods for Conditional Optimization. Ph. E. Gill, W. Murray (eds.) Moscow: Mir, 1977. 292 p.

Надійшла: 09.12.2021 / Прийнята: 23.12.2021 


\title{
ПРАКТИЧЕСКАЯ ЭФФЕКТИВНОСТЬ МЕТОДА ЕQR ДЛЯ РЕШЕНИЯ ЗАДАЧ ГЛОБАЛЬНОЙ ОПТИМИЗАЦИИ
}

\begin{abstract}
А. И. КОсОЛАП
Факультет компьютерных наук и инженерии, Украинский государственный химикотехнологический университет, Днепр, Украина, E-mail: anivkos@ua.fm

АннотАция. В работе проводится анализ практической эффективности метода точной квадратичной регуляризации. Проведен большой объем численных экспериментов по решению сложных мультимодальных тестовых и практических задач. Результаты численных экспериментов сравниваются с лучшими результатами, которые получены существующими методами глобальной оптимизации. Сравнительный анализ свидетельствует о значительно большей практической эффективности метода точной квадратичной регуляризации.

КлЮчЕВЫЕ СЛовА: мультимодальные задачи, глобальная оптимизация, численные эксперименты, метод точной квадратичной регуляризации.
\end{abstract}

